\title{
Metabolite Profiling Analysis of Conventional and Non-Conventional Extraction Methods on Secondary Metabolite from Peperomia pellucida (L.) Kunth using UPLC-QToF-MS/MS System
}

\author{
Islamudin Ahmad ${ }^{1,3}$, Kamarza Mulia², Arry Yanuar $^{3}$, Abdul Mun'im $^{3 *}$ \\ 'Laboratory of Pharmaceutical Research and Development of FARMAKA TROPIS, Faculty of Pharmacy, Mulawarman University, Samarinda, East Kalimantan, 75119 , \\ INDONESIA. \\ 2Department of Chemical Engineering, Faculty of Engineering, Universitas Indonesia, Depok, West Java, 16424, INDONESIA. \\ ${ }^{3}$ Department of Pharmaceutical Sciences, Faculty of Pharmacy, Universitas Indonesia, Depok, West Java, 16424, INDONESIA.
}

\begin{abstract}
Objective: The purpose of this study was to observe the difference of extraction method (both conventional and non-conventional) based on metabolite profile using UPLC-QToF-MS/MS system from Peperomia pellucida (L.) Kunth. Methods: Dried samples were extracted using the conventional maceration method and the optimum ofionic liquid-based microwave-assisted extraction (IL-MAE) methods.Metabolite profiling was performed using UPLC-QToF-MS/MS system with some modifications adjusted to the instrument condition. The data was analyzed using Masslynx 4.1 software. Results: based on the results, there were differences on metabolite profiling from both conventional and non-conventional extraction methods that was extraction method using organic solvent and ionic liquid solvent ([BMIM]BF ${ }_{4}$ at the optimum condition. The extract obtained using IL-MAE method had a peak depth with a well-separated Rt (retention time) value ranging from 0.5 to 7.5 min which means that the extracted compound was from polar to nonpolar properties. The extract obtained using maceration method, the peak spread on a separate Rt ranges from 2.5 to $7.5 \mathrm{~min}$. Also, both extracts obtained have different area under curve (AUC) values
\end{abstract}

with amount total of 22285 (IL-MAE) and 12679 (maceration), respectively, and showed the IL-MAE twice as large as that of the maceration. Conclusion: based on the results, conventional and non-conventional extraction method showed differences in metabolite profiling based on Rt value and mass spectrum $\mathrm{m} / \mathrm{z}$ of each peak.

Key words: Peperomia pellucida (L) Kunth, Hyphenated system, Ionic liquid-based microwave-assisted extraction, Maceration, Metabolite profiling

\section{Correspondence}

Abdul Mun'im, Department of Phar Maceutical Sciences, Faculty of Pharmacy, Universitas Indonesia, Depok, West Java, 16424, INDONESIA.

Phone: +62-852-1610-4550

Email: munimabdoel@gmail.com

DOI: 10.5530/jyp.2018.2s.8

\section{INTRODUCTION}

Peperomia pellucida (L.) Kunth herbs (Piperaceae family) has been known to contain secondary metabolites such as terpenoids, alkaloids, saponins, dan polyphenols. ${ }^{1}$ Some of them have been isolated (particularly polyphenolic groups) including pellucidin $\mathrm{A},{ }^{2}$ peperomins, secolignan, ${ }^{3}$ xanthone patuloside $\mathrm{A},{ }^{4}$ dillapiole, ${ }^{5}$ chromene, ${ }^{6}$ and quercetin. ${ }^{7}$ Also, the herbs have also been reported to have potential pharmacological properties. $^{8}$

The bioactive compound from natural products mainly from plants source can be extracted by conventional (including maceration, reflux, soxhlet, percolation) $)^{9}$ and non-conventional extraction methods (such as microwave-assisted extraction, ultrasonic-assisted extraction, supercritical fluid extraction, and so on). ${ }^{10}$ However, the use of extraction methods is strongly influenced by the type of solvent used.

Ionic liquid based microwave-assisted extraction (IL-MAE) continued to be developed and applied in the extraction secondary metabolites from natural products. This method was developed based on the selection of solvents with a green chemistry principle approach in exploring the metabolite constituent of natural products. The ionic liquid is chosen as solvent because it has the flexibility and potential to replace conventional organic solvents that are volatile, flammable, and toxic. ${ }^{11}$ Application of ionic liquid as a solvent to extracting secondary metabolite and optimization of the IL-MAE method of polyphenolics content extraction from this herb has been performed in previous studies. ${ }^{12-13}$

Metabolite profiling is intended to distinguish between the known compound (dereplication) and new molecule directly present in the crude extract. ${ }^{14}$ Metabolite profiling in crude extracts is not an easy work as natural materials show a very diverse form of structure. In some compounds, the atomic sequence and its stereochemical orientation must be elucidated by de novo. Consequently, the ability of a single analytical technique in profiling metabolite content in the crude extract to date does not exist. ${ }^{15}$ Innovative development strategies from metabolite profiling in crude extracts where the researcher can be facilitated by the hyphenated system found during the last decade. The potential for chemical screening strategies has been significantly enhanced by the recent development of the hyphenated technique, which is capable of generating efficient metabolite separation, along with valuable structural information both online and at-line. ${ }^{16}$

One of the instruments with the hyphenated system used to analyze metabolite profiling with high accuracy and validity ${ }^{17-18}$ from crude extract is UPLC-QToF-MS/MS tandem system. ${ }^{19}$ This method has been 
successfully used for metabolite profiling analysis in some medicinal plants such as metabolite profiling of bioactive compounds from Bidens pilosa, ${ }^{14}$ metabolites profiling secondary metabolites of Arabidopsis arabika, ${ }^{20}$ Analysis of steviol and its glycoside from Stevia rebaudiana leaves as a commercial sweetener, ${ }^{21}$ metabolite profiling of polyphenols from Vaccinium berries. ${ }^{22}$ While the metabolite profiling analysis of P. pellucida herb (using both conventional and non-conventional extraction) has not been reported.

Active compound isolation from $P$. pelucida herb requires specific techniques to obtain the compound optimally. Development of extraction methods (both conventional and non-conventional) and metabolite profiling with hyphenated systems to achieve the target compounds. This study aimed to know the difference of extraction method (both conventional maceration and non-conventional IL-MAE) based on metabolite profile analysis using UPLC-QToF-MS/MS system.

\section{MATERIALS AND METHODS}

\section{Materials}

Wild herb materials of $P$. pellucida were collected from the oil palm plantation at Baras sub-district, North Mamuju, West Sulawesi, Indonesia, and were identified at the Herbarium Bogoriense, Bogor, West Java, Indonesia. The fresh sample was washed, and dried at $50-60^{\circ} \mathrm{C}$ using drying oven, and the dried sample was powdered using a grinder. The powder obtained was stored at a cold temperature until analysis.

\section{Material and General Equipments}

The materials used in this study include n-hexane, ethyl acetate, aquadest (PT. Smart Lab Indonesia, Indonesia), 1-butyl-3-methylimidazolium tetrafluoroborate (Cheng Jie Chemical Co. LTD, China). Acetonitrile (LiChrosolv ${ }^{\circledR}$ for HPLC), Ethanol (Chromosolv ${ }^{\circledR}$ for HPLC), formic acid (Merck, Germany). The general equipment used in this study were Modena Microwave 900 Watt (Buono-MV3002), Rotary Evaporator (Buchi, Germany), UPLC-QToF-MS/MS System (Waters, USA), as well as equipment for maceration.

\section{Extraction procedure}

The extraction process was conducted using conventional (maceration method) and non-conventional (ILMAE method) as follows:

\section{Conventional Maceration Method}

Dried sample (1 kg) was macerated using n-hexane solvent for $24 \mathrm{~h}$, and extraction process was performed for 4-6 times. Next, the residual of samples was re-macerated using ethyl acetate with the same condition. The extract solution was evaporated using a rotary evaporator to obtain a dried extract. ${ }^{12}$

\section{Non-conventional IL-MAE Method}

For extraction process with the optimum ILMAE method was performed based on the previous study. ${ }^{12,23}$ including microwave power, extraction time, ionic liquid concentration, and liquid-solid ratio had been involved. Response surface methodology and Box Behnken design were used to obtain predictive model (multivariate quadratic regression equation Briefly,30 grams of dried sample was extracted using the optimum condition of IL-MAE method with [BMIM] $\mathrm{BF}_{4}$ as a solvent. The optimum condition of IL-MAE method was performed using ionic liquid concentration of $0.79 \mathrm{~mol} / \mathrm{l}$, the liquid-solid ratio of $11 \mathrm{ml} / \mathrm{g}$ sample, extraction time of $20 \mathrm{~min}$, and microwave power of $30 \% \mathrm{Watt}^{23}$ For analysis, the extraction process was performed four times.

\section{Metabolite profiling analysis}

For determination of metabolite profiling was performed using UPLC-QToF-MS/MS System according to the literature, ${ }^{14,17,22,24}$ with some modification adjusting to the instrument condition. Briefly, liquid chromatographic (LC) separation was performed using Xevo G2 ACQUITY with BEH C ${ }_{18}$ column $1.7 \mu \mathrm{m}, 2.1$ x $50 \mathrm{~mm}$ (Waters Corp, Milford, MA, USA). Autosampler Tray and columns temperature was maintained at $40^{\circ} \mathrm{C}$, the mobile phase consisting of water containing $0.1 \%$ formic acid (A) and acetonitrile containing 0.1 formic acids (B) was used at a flow rate $0.3 \mathrm{ml} / \mathrm{min}$. The elution gradient can be seen in Table 1 .

Data acquisition was processed with Masslynx 4.1 software. Extract sample $(10 \mathrm{mg}$ ) was weighed and dissolved in $100 \mathrm{ml}$ methanol (LC-MS grade). One $\mathrm{ml}$ of the sample solution was taken into the Effendorf tube and was centrifuged at $13000 \mathrm{rpm}$ for $10 \mathrm{~min}$. The supernatant was separated into another Effendorf tube. The sample injection volume was set at $5 \mu \mathrm{l}$ and the total running time was $10 \mathrm{~min}$. The UPLC output system was connected to the mass spectrometer via the ESI interface and was operated in the positive ion detection mode. Nitrogen was used for desolvation of $500 \mathrm{~L} / \mathrm{h}$; the cone gas was set at $16 \mathrm{~L} / \mathrm{h}$. The capillary voltage was set at $3 \mathrm{kV}$, source temperature $110^{\circ} \mathrm{C}$, and desolvation temperature $300^{\circ} \mathrm{C}$.

\section{RESULTS}

For the results test of profiling metabolite using the same gradient conditions that were the mobile phase with the ratio between aquadest and acetonitrile (containing 0.1\% formic acid) from 95:5 to 5:95 for 9 min as shown in Table 1.

As can be seen in Figure 1 and 2 demonstrated Total Ion Chromatogram (TIC) with peak smoothing and peak area integration (A) and TIC with peak smoothing (B) that showed difference of metabolite profiling from both method that was extraction method using organic solvent and ionic liquid solvent ([BMIM] $\left.\mathrm{BF}_{4}\right)$ at the optimum condition of the instrument. In Figure 1 a peak depth with a well-separated Rt (retention time) value ranging from 0.5 to $7.5 \mathrm{~min}$ was shown, which means that the extracted compound was from polar to nonpolar properties. In Figure 2, the peak spread on a separate Rt ranges from 2.5 to $7.5 \mathrm{~min}$. While in the min of 0.5 to 2.4 there was no peak. It indicates that the compound extracted by maceration method using ethyl acetate have nonpolar properties.

From both extracts based on different extraction methods (i.e., maceration and IL-MAE) the different result of metabolite profiling was obtained. Shown in Figure 1 which was the result of metabolite profiling of the extract obtained by IL-MAE, there was a peak especially in 0.4 to $3.0 \mathrm{~min}$ which was not present in the extract obtained by maceration (as can be seen in Figure 2). Whereas in Figure 2 there were peaks, especially at strong peak with Rt of $4.52-5.60$ min while peak on metabolite profiling results from the extract obtained by IL-MAE show peak which was weak even not exist. While in the peak with Rt 6.20 there were on both extracts. Also, both extracts obtained has different AUC values in which extracts

\section{Table 1: The elution gradient for metabolite profiling analysis using} UPLC- QToF-MS/MS System (Waters).

\begin{tabular}{cccc}
\hline No. & Time (Minute) & $\% \mathrm{~A}$ & $\% \mathrm{~B}$ \\
\hline 1 & 0 & 95 & 5 \\
2 & 1 & 95 & 5 \\
3 & 6 & 0 & 100 \\
4 & 7 & 0 & 100 \\
5 & 7.5 & 95 & 5 \\
6 & 9 & 95 & 5 \\
\hline
\end{tabular}

Where $\mathrm{A}$ is the mobile phase consisting of water containing $0.1 \%$ formic acid and $\mathrm{B}$ is the mobile phase consisting of acetonitrile containing $0.1 \%$ formic acid. 


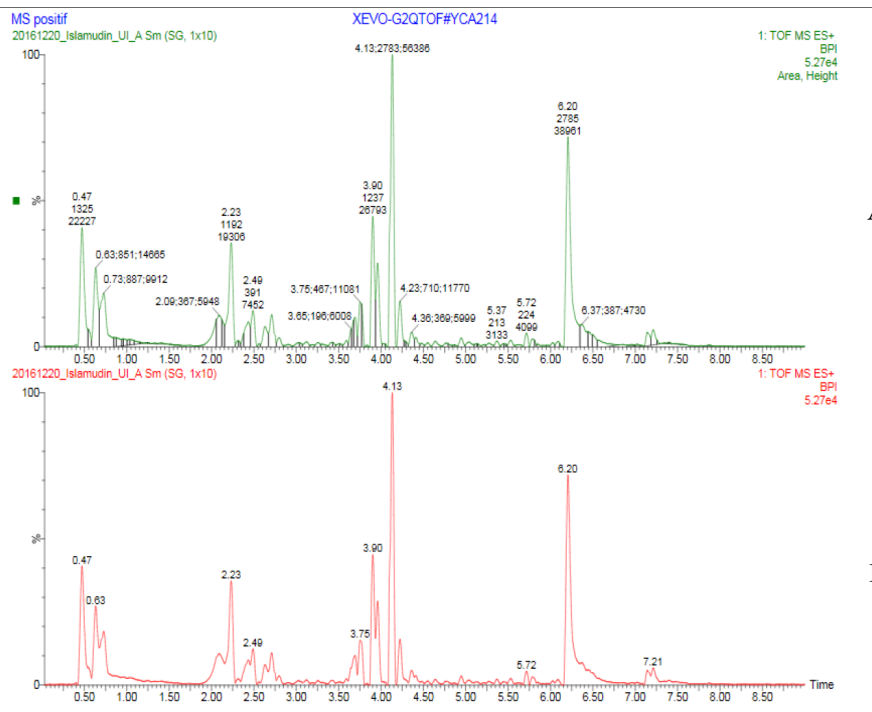

Figure 1: Peaks data of metabolite profiling analysis from extracts were obtained by IL-MAE method (non-conventional method) with [BMIM] $\mathrm{BF}_{4}$ as a solvent using UPLC- QToF-MS/MS System.

Where $A$ is Total ion chromatogram (TIC) with peak smoothing and peak area integration; $B$ is Total ion chromatogram with smoothing.

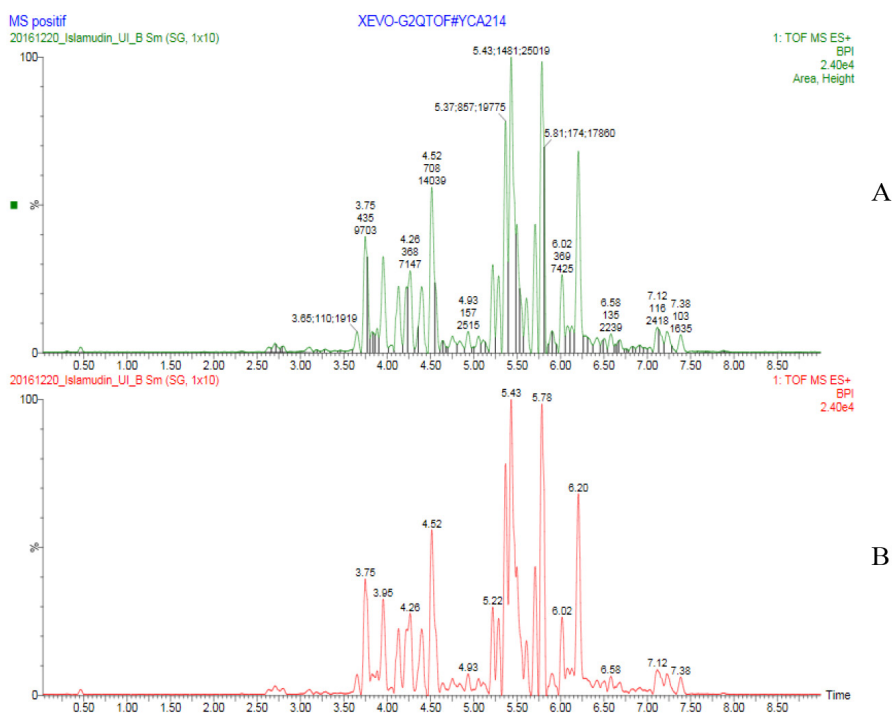

Figure 2: Peaks data of metabolite profiling analysis from extracts were obtained by maceration method (conventional method) with ethyl acetate as a solvent using UPLC- QToF-MS/MS System.

Where $A$ is Total ion chromatogram (TIC) with peak smoothing and peak area integration; $B$ is Total ion chromatogram with smoothing.

Table 2: Results of UPLC-QToF-MS/MS (m/z value) spectrum of extract was obtained using IL-MAE method (non-conventional method).

\begin{tabular}{|c|c|c|c|}
\hline No & $\begin{array}{l}\text { Retention } \\
\text { Time (Rt) }\end{array}$ & $\min$ & $\mathrm{m} / \mathrm{zvalue}$ \\
\hline \multirow[t]{5}{*}{1} & $0.4-2.3$ & 0.468 & $139.1816 ; 140.1761 ; 141.1166 ; 323.3341 ; 507.4559 ; 691.6055 ; 875.7525 ; 1059.8871 ; 1244.0045 ; 1428.1177$ \\
\hline & & 0.625 & $139.1782 ; 140.1761 ; 364.3413 ; 365.3409 ; 366.3379 ; 591.4858 ; 626.9603 ; 817.6363 ; 922.6903 ; 1043.7958 ; 1268.9130 ; 1496.0017$ \\
\hline & & 0.730 & $139.1768 ; 140.1758 ; 365.3379 ; 410.1645 ; 591.4912 ; 626.9582 ; 817.6421 ; 922.6833 ; 1043.7909 ; 1268.9534 ; 1495.0270$ \\
\hline & & 2.082 & $211.2456 ; 212.2475 ; 251.2299 ; 354.1744 ; 486.2294$ \\
\hline & & 2.232 & $211.2516 ; 212.2471 ; 251.237 ; 355.1892 ; 565.2423 ; 647.2996 ; 818.2544 ; 1054.0790$ \\
\hline \multirow[t]{5}{*}{2} & $2.3-2.9$ & 2.436 & $223.2466 ; 245.2317 ; 252.2227 ; 340.1905 ; 565.2446 ; 603.3232$ \\
\hline & & 2.490 & $171.1478 ; 245.2336 ; 246.2336 ; 251.2426 ; 433.2215 ; 481.2777 ; 595.3393$ \\
\hline & & 2.669 & $195.1249 ; 196.1307 ; 283.2699 ; 447.2441 ; 593.3315 ; 685.3773$ \\
\hline & & 2.715 & $195.1291 ; 196.1336 ; 402.2793 ; 477.2263 ; 522.3278 ; 687.3209$ \\
\hline & & 2.805 & $179.1615 ; 219.1680 ; 308.3018 ; 403.2110 ; 566.4335 ; 724.3237 ; 769.3845 ; 911.3472 ; 1027.4069 ; 1174.3456 ; 1494.6885$ \\
\hline \multirow[t]{5}{*}{3} & $2.9-3.5$ & 2.919 & $201.2108 ; 219.2210 ; 235.2005 ; 323.3064 ; 407.2352 ; 430.2371 ; 531.3644 ; 650.2902 ; 847.4064 ; 899.3586$ \\
\hline & & 3.091 & $151.1069 ; 209.1243 ; 211.1613 ; 276.1473 ; 385.2653 ; 407.2422 ; 515.3213 ; 647.4405 ; 733.3910$ \\
\hline & & 3.109 & $177.1185 ; 207.1454 ; 314.2209 ; 331.2057 ; 407.2459 ; 548.3253 ; 549.3280 ; 671.3453 ; 783.3347 ; 883.4658$ \\
\hline & & 3.348 & $207.1514 ; 225.1598 ; 305.2462 ; 421.2552 ; 529.3532 ; 549.3170 ; 685.3718 ; 685.3718 ; 773.4330 ; 957.6433 ; 1175.5614$ \\
\hline & & 3.431 & $195.1424 ; 271.1469 ; 313.1953 ; 373.2277 ; 375.2440 ; 478.3654 ; 593.3487$ \\
\hline \multirow[t]{6}{*}{4} & $3.5-4.5$ & 3.685 & $212.2958 ; 304.3846 ; 313.1908 ; 318.3595 ; 529.3406 ; 625.3709 ; 754.4578 ; 841.4797 ; 975.5499$ \\
\hline & & 3.756 & $207.1587 ; 235.1687 ; 236.1685 ; 403.2746 ; 404.2841 ; 529.3494 ; 753.4700 ; 827.4679 ; 952.3814 ; 1050.5581 ; 1189.4120 ; 1438.4369$ \\
\hline & & 3.900 & $225.2053 ; 384.4238 ; 285.4135 ; 332.4052 ; 525.2990 ; 561.3804 ; 739.4343 ; 817.4390 ; 949.5057 ; 1075.5227$ \\
\hline & & 3.953 & $300.1483 ; 315.1792 ; 316.1764 ; 332.3993 ; 466.3031 ; 629.3246 ; 739.4461 ; 785.4274 ; 963.5539 ; 999.5621 ; 1111.6162$ \\
\hline & & 4.129 & $195.1401 ; 312.4749 ; 313.4536 ; 360.4524 ; 581.3390 ; 653.3799 ; 739.4486 ; 869.4777 ; 986.4565 ; 1124.5309$ \\
\hline & & 4.218 & $195.1435 ; 322.4378 ; 329.1913 ; 330.1898 ; 331.2008 ; 441.4445 ; 619.3845 ; 739.4498 ; 949.5218 ; 1174.6296 ; 1286.6456$ \\
\hline \multirow[t]{5}{*}{5} & & 4.959 & $149.0787 ; 277.2780 ; 301.2099 ; 522.4457 ; 623.3851 ; 766.6262 ; 898.7619 ; 987.7861 ; 1174.6445 ; 1313.7004 ; 1495.8024$ \\
\hline & & 5.714 & $\begin{array}{c}139.1722 ; 251.1402 ; 308.3557 ; 309.3383 ; 419.3854 ; 565.3870 ; 581.3549 ; 637.4206 ; 638.4244 ; 639.4299 ; 858.8097 ; 896.7033 ; \\
1053.4819 ; 1272.7568 ; 1460.0713\end{array}$ \\
\hline & & 6.218 & $149.0884 ; 150.0798 ; 391.3789 ; 413.3726 ; 429.3433 ; 457.3602 ; 638.7296 ; 803.6777 ; 872.8376 ; 1019.749$ \\
\hline & & 7.155 & $\begin{array}{c}139.1703 ; 149.0715 ; 370.3681 ; 413.3850 ; 607.5057 ; 663.5709 ; 843.6861 ; 887.7139 ; 888.7165 ; 889.7233 ; 890.7280 ; 985.9030 ; \\
1326.0479\end{array}$ \\
\hline & & 7.206 & $\begin{array}{c}139.1727 ; 370.3823 ; 413.3847 ; 677.5908 ; 843.6845 ; 871.7186 ; 872.7230 ; 873.7269 ; 874.7251 ; 1090.8916 ; 1155.9614 ; 1342.0386 ; \\
1470.1021\end{array}$ \\
\hline
\end{tabular}


Ahmad, et al:: Metabolite Profiling Analysis on Secondary Metabolite from Peperomia pellucida (L) Kunth Herb Extracts

Table 3: Results of LC-MS (m/z value)spectrum of extract was obtained using maceration method (conventionalextraction method)." replaced with "Results of UPLC-QToF-MS/MS (m/z value) spectrum of extract was obtained using maceration method (conventional extraction method).

\begin{tabular}{|c|c|c|c|}
\hline No & $\begin{array}{l}\text { Retention } \\
\text { Time (Rt) }\end{array}$ & Min & $\mathrm{m} / \mathrm{zvalue}$ \\
\hline \multirow[t]{5}{*}{1} & $3.34-4.3$ & 3.635 & $181.1697 ; 219.1656 ; 304.3615 ; 387.3539 ; 753.4727 ; 814.4013 ; 924.4348 ; 1206.4136 ; 1285.6440$ \\
\hline & & 3.756 & $219.1701 ; 235.11686 ; 236.1662 ; 329.2194 ; 403.2748 ; 427.2461 ; 632.3526 ; 827.4625 ; 81.4370 ; 976.5239$ \\
\hline & & 3.950 & $219.1695 ; 315.1745 ; 316.1740 ; 427.2531 ; 553.3780 ; 682.2105 ; 773.4325$ \\
\hline & & 4.140 & $\begin{array}{c}219.1689 ; 312.4491 ; 313.4427 ; 315.1689 ; 427.2712 ; 643.3893 ; 720.4321 ; 947.6596 ; 983.5687 ; 1143.5848 ; 1324.7644 ; \\
1436.8271\end{array}$ \\
\hline & & 4.272 & $219.1684 ; 221.1547 ; 329.1894 ; 330.1904 ; 427.2780 ; 627.3904 ; 711.3359 ; 803.5481 ; 967.4610$ \\
\hline \multirow[t]{5}{*}{2} & $4.3-5.3$ & 4.400 & $219.1678 ; 221.1811 ; 299.1703 ; 304.2689 ; 411.2731 ; 627.3802 ; 699.4662 ; 737.5193 ; 880.5945$ \\
\hline & & 4.512 & $221.1875 ; 222.1843 ; 411.2766 ; 553.4916 ; 627.3677 ; 795.5170 ; 833.5162 ; 981.5439 ; 1091.9723$ \\
\hline & & 4.941 & 203.2382; 219.1720; 221.1771; 387.2785; 419.3132; 639.3691; 641.3979; 810.6937; 939.6212; 1031.7057 \\
\hline & & 5.213 & $\begin{array}{c}219.1744 ; 275.2413 ; 387.2763 ; 607.3751 ; 610.3864 ; 611.3885 ; 669.4666 ; 879.4844 ; 1022.9031 ; 1217.7123 ; 1269.7792 ; \\
1494.8412\end{array}$ \\
\hline & & 5.277 & $\begin{array}{c}219.1739 ; 386.3646 ; 607.3882 ; 609.4003 ; 635.3800 ; 626.3835 ; 627.3950 ; 782.6851 ; 829.6377 ; 1029.4808 ; 1233.7205 ; \\
1357.7954 ; 1434.646\end{array}$ \\
\hline \multirow[t]{5}{*}{3} & $5.3-5.85$ & 5.363 & $219.1739 ; 387.2882 ; 509.3809 ; 535.3666 ; 610.3857 ; 611.3904 ; 782.6791 ; 879.5152 ; 1086.8999 ; 1218.17064 ; 1318.7473$ \\
\hline & & 5.438 & $219.1713 ; 412.3825 ; 535.3679 ; 593.3825 ; 594.3857 ; 609.3829 ; 625.4382 ; 782.6993 ; 1127.7306 ; 1185.7092 ; 1354.2301$ \\
\hline & & 5.560 & $\begin{array}{c}219.1709 ; 221.1738 ; 341.2921 ; 414.4041 ; 415.4006 ; 535.3690 ; 593.3873 ; 594.3924 ; 743.4485 ; 829.6261 ; 919.6580 ; \\
1197.0258\end{array}$ \\
\hline & & 5.714 & $203.2279 ; 219.1732 ; 308.3825 ; 309.3676 ; 535.3777 ; 593.3900 ; 637.4399 ; 829.6188 ; 919.6422 ; 1256.0709 ; 1313.7601$ \\
\hline & & 5.785 & $219.1567 ; 334.4149 ; 335.3990 ; 356.3844 ; 607.4096 ; 689.6401 ; 813.6051 ; 903.6359$ \\
\hline \multirow[t]{7}{*}{4} & $5.85-7.5$ & 5.907 & $\begin{array}{c}203.2272 ; 219.1738 ; 220.1809 ; 348.4148 ; 349.4074 ; 387.2815 ; 611.5715 ; 612.5655 ; 829.6135 ; 905.6819 ; 1097.9205 ; \\
1188.9225 ; 1376.1067\end{array}$ \\
\hline & & 6.014 & $219.1734 ; 221.1704 ; 336.5163 ; 362.4325 ; 427.3952 ; 551.4983 ; 815.6162 ; 887.6426 ; 937.7065 ; 1042.7949 ; 1167.8545$ \\
\hline & & 6.204 & $149.0832 ; 219.1691 ; 387.2775 ; 413.3725 ; 429.3481 ; 613.5667 ; 797.6502 ; 865.6614 ; 961.7382 ; 1065.7802$ \\
\hline & & 6.491 & $\begin{array}{c}219.1746 ; 335.3382 ; 387.2788 ; 429.4297 ; 613.5734 ; 797.6614 ; 905.7272 ; 921.7256 ; 922.7267 ; 923.7308 ; 1033.8214 ; \\
1159.9659\end{array}$ \\
\hline & & 7.141 & $\begin{array}{c}219.1692 ; 370.3982 ; 541.3345 ; 609.3832 ; 871.7190 ; 903.7157 ; 904.7144 ; 905.7189 ; 906.7194 ; 1081.8163 ; 1275.9602 ; \\
1497.1693\end{array}$ \\
\hline & & 7.238 & $\begin{array}{c}219.1591 ; 370.3939 ; 593.3926 ; 705.6019 ; 813.7011 ; 871.7213 ; 872.7220 ; 873.7233 ; 874.7306 ; 1093.7841 ; 1166.9430 ; \\
1296.0737 ; 1433.9531\end{array}$ \\
\hline & & 7.395 & $219.1620 ; 370.3899 ; 565.3514 ; 705.6183 ; 813.7059 ; 814.7114 ; 815.7146 ; 888.7054 ; 1093.8440 ; 1166.9338 ; 1412.1720$ \\
\hline
\end{tabular}

were extracted by IL-MAE and maceration methods with amount total of 22285 and 12679, respectively, where the extracts of IL- MAE was twice as large as that of the extracts of maceration method. replaced with "method. The $\mathrm{m} / \mathrm{z}$ values of each peak based on different Rt values demonstrated in Table 2 for IL-MAE extract and Table 3 for ethyl acetate extract.

\section{DISCUSSION}

In this study, non-conventional extraction was performed using ILMAE method based on a combination of optimum extraction condition parameters, as well as 18.6 min extraction times, $30 \%$ Watt microwave

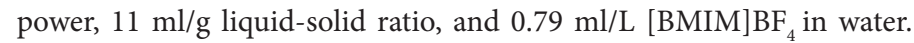
$[\mathrm{BMIM}] \mathrm{BF}_{4}$ was chosen because based on the comparison of effectiveness in extracting the polyphenol class from this herb in the previous study, and the liquid ionic solvent was the best solvent to extract the target compound. ${ }^{23}$ including microwave power, extraction time, ionic liquid concentration, and liquid-solid ratio had been involved. While the conventional extraction using the maceration method with n-hexane then followed by ethyl acetate. Each extract obtained was dried and stored in a cool place and prepared for analysis.
Strategies for the analysis and identification of natural plant compounds with profiling metabolite approach using UPLC-QToF-MS/MS tandem system based on peaks at a particular retention time (Rt) as data and compared with the database, ${ }^{19}$ particularly natural product research. In metabolite profiling analysis, a very high resolution of chromatography was required to detect the metabolites of the associated matrix complex. ${ }^{26}$ The reduction of particle size in chromatography allows higher separation efficiency and shorter analysis times. ${ }^{16}$

In this study, metabolite profiling analysis was performed only limited to the results of the investigation using UPLC-QToF-MS/MS tandemsystem and obtained peak distribution from each extract at the same eluent condition based on total ion chromatogram (TIC) with peak smoothing and peak area integration. The $\mathrm{m} / \mathrm{z}$ spectrum value in each peak indicates compound predictions according to the experimental molecular weight approach as can be seen in Table 2 and Table 3. This study does not use standards as controls, however, focusing only on the differences in the components present in each extract based on the Rt and $\mathrm{m} / \mathrm{z}$ spectrum value.

Based on the results of metabolite profiling analysis, it was shown that the results of spectrum $\mathrm{m} / \mathrm{z}$ gave different peaks on each extract. However, in this study, the $\mathrm{m} / \mathrm{z}$ spectrum cannot be determined precisely given the absence of a comparison standard to be used as a benchmark on each 
peak produced. In addition, these profiles correlate with total polyphenolics content from extracts of each method. ${ }^{13,23}$ Therefore, only the optimum conditions obtained from the instrument used to separate the class of compounds contained in the extract based on the technique used, and the preliminary data related to the use of liquid ionic solvents as an alternative solution with a green chemical principles approach.

\section{CONCLUSION}

Based on the above results, metabolite profiling was determined and analyzed using UPLC- QToF-MS/MS System and both conventional and non-conventional extraction method showed differences in metabolite profiling based on Rt value and mass spectrum $\mathrm{m} / \mathrm{z}$ of each peak.

\section{ACKNOWLEDGEMENT}

This study was funded by Faculty of Pharmacy, Mulawarman University via a grant "Hibah Fakultas Farmasi UNMUL 2017." Many thank Head Laboratory of Pharmacognosy-Phytochemistry, Faculty of Pharmacy, Universitas Indonesia for providing facilities.

\section{CONFLICT OF INTEREST}

The author declares that he has no conflict of interest.

\section{ABBREVIATIONS}

P. pellucida: Peperomia pellucida (L.) Kunth; IL-MAE: Ionic Liquid Microwave-Assisted Extraction; [BMIM]BF4: 1-butyl-3-methylimidazolium tetrafluoroborate; LC: liquid Chromatography; HPLC: High Performance Liquid Chromatography; UPLC-QToF-MS/MS: UltraPerformance Liquid Chromatography quadrupole time of flight mas spectrometry; Rt: Retention time; TIC: Total Ion Chromatogram; AUC: Area Under Curve; $\mathbf{m} / \mathbf{z}$ : mass per atomic charge.

\section{SUMMARY}

- There were differences on profiling metabolite from both conventional and non-conventional extraction methods that was extraction method using organic solvent and ionic liquid solvent ([BMIM]BF4) at the optimum condition.

- The extract obtained using IL-MAE method had a peak depth with a well-separated Rt (retention time) value ranging from 0.5 to 7.5 minutes which means that the extracted compound was from polar to non-polar properties.

- The extract obtained using maceration method, the peak spread on a separate Rt ranges from 2.5 to 7.5 minutes.

- Both extracts obtained have different area under curve (AUC) values with amount total of 22285 (IL-MAE) and 12679 (maceration), respectively, and showed the IL-MAE twice as large as that of the maceration.

- Conventional and non-conventional extraction method showed differences in metabolite profiling based on Rt value and mass spectrum $\mathrm{m} / \mathrm{z}$ of each peak.

\section{REFERENCES}

1. Mensah JK, Okoli RI, Turay AA, Ogie-Odia EA. Phytochemical analysis of medicinal plants used for the management of hypertension by Esan people of Edo State, Nigeria. Ethnobot Leafl. 2009;13(12):73-87.

2. Verma RS, Padalia RC, Goswani P, Chauhan A. Essential oil composition of Peperomia pellucida (L.) from India. J Essent Oil Res. 2014;26(1):29-33. doi:10. 1080/10412905.2013.822431.

3. Xu S, Li N, Ning MM, Zhou CH, Yang QR, Wang MW. Bioactive Compounds from Peperomia pellucida. J Nat Prod. 2006;69(2):247-50. doi:10.1021/np050457s.
4. Khan A, Rahman M, Islam S. Isolation and Bioactivity of a Xanthone Glycoside from Peperomia pellucida. Life Sci Med Res. 2010;2010:1-10.

5. Rojas-Martínez R, Arrieta J, Cruz-Antonio L, Arrieta-Baez D, Velázquez-Méndez AM, Sánchez-Mendoza ME. Dillapiole, isolated from Peperomia pellucida, shows gastroprotector activity against ethanol-induced gastric lesions in wistar rats. Molecules. 2013;18(9):11327-37. doi:10.3390/molecules180911327.

6. Susilawati Y, Nugraha R, Muhtadi A, Soetardjo S, Supratman U. (S)-2-Methyl2-(4-methylpent-3-enyl)-6-(propan-2-ylidene)-3,4,6,7-tetrahydropyrano[4,3-g] chromen-9(2H)-one. Molbank. 2015;2015(2):1-6. doi:10.3390/M855.

7. Kurniawan A, Saputri FC, Ahmad I, Mun'im A. Isolation of angiotensin converting enzyme (ACE) inhibitory activity quercetin from Peperomia pellucida. Int J PharmTech Res. 2016;9(7):115-21.

8. Mun'im A, Nurpriantia N, Setyaningsih R, Syahdi RR. Optimization of microwave-assisted extraction of active compounds, antioxidant activity, and angiotensin-converting enzyme (ACE) inhibitory activity from Peperomia pellucida (L.) Kunth. J Young Pharm. 2017;9(1):73-8. doi:10.5530/jyp.2017.

9. Hanani E. Analisis Fitokimia. Jakarta: Penerbit Buku Keokteran, EGC. 2015

10. Khoddami A, Wilkes M, Roberts T. Techniques for analysis of plant phenolic compounds. Molecules. 2013;18(3):2328-75. doi:10.3390/molecules 18022328.

11. Jessop PG, Jessop D, Fu D, Phan L. Solvatochromic parameters for solvents of interest in green chemistry. Green Chem. 2012;14(5):1245-59. doi:10.1039/ c2gc16670d.

12. Ahmad I, Yanuar A, Mulia K, Mun'im A. Application of ionic liquid-based microwave-assisted extraction of the secondary metabolite from Peperomia pellucida (L) Kunth. Pharmacogn J. 2017:9(2):227-34. doi:10.5530/pj.2017.2.38.

13. Ahmad I, Yanuar A, Mulia K, Mun'im A. Application of ionic liquid as a green solvent for polyphenolics content extraction of Peperomia pellucida (L) Kunth herb. J Young Pharm. 2017;9(4):S1-S4. doi:10.5530/jyp.2017.

14. Chiang YM, Chuang DY, Wang SY, Kuo YH, Tsai PW, Shyur LF. Metabolite profiling and chemopreventive bioactivity of plant extracts from Bidens pilosa. J Ethnopharmacol. 2004;95(2-3):409-19. doi:10.1016/j.jep.2004.08.010.

15. Kaufmann A. Combining UHPLC and high-resolution MS: A viable approach for the analysis of complex samples? TrAC - Trends Anal Chem. 2014:63:113-28. doi:10.1016/j.trac.2014.06.025.

16. Chechinel-Filho V. Plants Bioactives and Drug Discovery: Principles, Practice, and Perspectives. Hoboken, New Jersey: John Wiley and Sons, Inc. 2012.

17. Cuthbertson DJ, Johnson SR, Piljac-Žegarac J, Kappel J, Schäfer S, Wüst M, et al. Accurate mass-time tag library for LC/MS-based metabolite profiling of medicinal plants. Phytochemistry. 2013;91:187-97. doi:10.1016/j.phytochem.2013.02.018.

18. González RR, Fernández RF, Luis J, Vidal JL, Frenich AG, Pérez ML. Development and validation of an ultra-high performance liquid chromatography-tandem mass-spectrometry (UHPLC-MS/MS) method for the simultaneous determination of neurotransmitters in rat brain samples. J Neurosci Methods J. 2011;198(2):187-94. doi:10.1016/j.jneumeth.2011.03.023.

19. Wolfender JL, Marti G, Thomas A, Bertrand S. Current approaches and challenges for the metabolite profiling of complex natural extracts. J Chromatogr A. 2015;1382:136-64. doi:10.1016/j.chroma.2014.10.091

20. D'Auria JC, Gershenzon J. The secondary metabolism of Arabidopsis thaliana: growing like a weed. Curr Opin Plant Biol. 2005;8(3):308-16. doi:10.1016/j pbi.2005.03.012.

21. Gardana C, Scaglianti M, Simonetti P. Evaluation of steviol and its glycosides in Stevia rebaudiana leaves and commercial sweetener by ultra-high-performance liquid chromatography-mass spectrometry. J Chromatogr A. 2010;1217(9):1463-70. doi:10.1016/j.chroma.2009.12.036.

22. Prencipe FP, Bruni R, Guerrini A, Rossi D, Benvenuti S, Pellati F. Metabolite profiling of polyphenols in Vaccinium berries and determination of their chemopreventive properties. J Pharm Biomed Anal. 2014;89:257-67. doi:10.1016/j.jpba.2013.11.016

23. Ahmad I, Yanuar A, Mulia K, Mun'im A. Optimization of ionic liquid-based microwave-assisted extraction of polyphenolic content from Peperomia pellucida $(L)$ Kunth using response surface methodology. Asian Pac J Trop Biomed. 2017;7(7):660-5. doi:10.1016/j.apjtb.2017.06.010.

24. Grata E, Boccard J, Guillarme D, et al. UPLC - TOF-MS for plant metabolomics A sequential approach for wound marker analysis in Arabidopsis thaliana \&. J Chromatogr BJ. 2008;871(2):261-70. doi:10.1016/j.jchromb.2008.04.021.

25. Hafidz KA, Puspitasari N, Azminah, Yanuar A, Artha Y, Mun'im A. HMG-CoA reductase inhibitory activity of Gnetum gnemon seed extract and identification of potential inhibitors for lowering cholesterol level. J Young Pharm. 2017;9(4):559-65. doi:10.5530/jyp.2017.

26. Creek DJ, Dunn WB, Fiehn O, et al. Metabolite identification: are you sure? And how do your peers gauge your confidence? Metabolomics. 2014;10(3):350-3. doi:10.1007/s11306-014-0656-8

\footnotetext{
Article History: Submission Date : 29-11-2017 ; Revised Date : 28-01-2018; Acceptance Date : 14-02-2018.

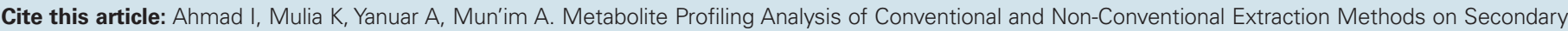
Metabolite from Peperomia pellucida (L.) Kunth Using .UPLC-QToF-MS/MS System. J Young Pharm. 2018;10(2)Suppl:s40-s44.
} 